\title{
UMA ANÁLISE DAS CONDIÇŌES PARA A IMPLEMENTAÇÃO DE POLÍTICAS DE EDUCAÇÃO INCLUSIVA NO BRASIL E NA INGLATERRA
}

\author{
Adriana Laplane*
}

\begin{abstract}
RESUMO: $\mathrm{O}$ artigo analisa as condiçōes de implementação de políticas de educação inclusiva no Brasil e no Reino Unido. Essas políticas inserem-se em um movimento de características excludentes que tem afetado a sociedade ocidental desde o período posterior à Segunda Guerra Mundial. No sentido oposto ao desse movimento excludente, as políticas inclusivas afirmam a necessidade de garantir educação a todos os indivíduos de uma sociedade. A implementação dessas políticas, nos dois países considerados, é pontuada por um conjunto de leis e documentos oficiais que visa a especificar as ações inclusivas. As práticas, entretanto, esbarram tanto nos conflitos e tensões gerados pelas condições sociais gerais, como nas propriedades dos sistemas educacionais. $\mathrm{O}$ artigo argumenta em favor de uma melhor compreensão das condiçôes de implementação das políticas inclusivas, de modo que o educador possa estabelecer, assim, as prioridades no seu contexto de atuação.
\end{abstract}

Palavras-chave: Inclusão. Políticas públicas. Educação especial.

AN ANALYSIS OF THE CONDITIONS FOR THE IMPLEMENTATION OF POLICIES OF INCLUSIVE EDUCATION IN BRAZIL AND IN ENGLAND

ABSTRACT: This paper analyses the conditions for the implementation of policies of inclusive education in Brazil and in the United Kingdom of England. These policies are inserted in a movement of exclusive characteristics that has affected the western societies since the Second World War. Opposing to this movement that excludes persons and groups from the world of work, consumption and social rights, inclusive policies affirm the necessity of providing education to all individuals in a society. The implementation of these poli-

* Professora da Faculdade de Ciências Médicas da Universidade Estadual de Campinas (UNICAMP). E-mail: adrifri@fcm.unicamp.br

Educ. Soc., Campinas, vol. 27, n. 96 - Especial, p. 689-715, out. 2006

Disponível em <http://www.cedes.unicamp.br> 
Uma análise das condiçôes para a implementação de políticas de educação...

cies, in both countries considered is regulated by laws and official documents that aim at specifying the educational actions to be taken by the educational systems. Inclusive practices, however, face barriers derived from the conflicts and tension generated by the general social conditions as well as from the properties of educational systems. These, generally, have not been designed to offer an education that meets different kinds of needs. The paper argues in favor of a better understanding of the conditions under which inclusive policies are implemented. The analysis of these conditions aims to contribute with the process of decision-making by educators, and to help them to establish the priorities and to choose the proper tools for educational practice.

Key words: Inclusion. Public policies. Special education.

O contexto do debate: a dinâmica social da inclusão e da exclusão nos países desenvolvidos

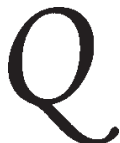

uando se fala em "inclusão", é interessante recorrer a uma perspectiva histórica e sociológica que nos lembre das condições que conformaram essa situação. Hobsbawm (1994), por exemplo, argumenta que a partir da segunda metade do século XX houve um movimento que transformou uma sociedade de traços inclusivos em uma sociedade excludente. Young (1999, p. 2) define este movimento como o trânsito "da estabilidade e homogeneidade para uma sociedade excludente de divisão e mudança”. Aderindo à idéia de Hobsbawm de que o período de pós-guerra significou uma "era de ouro" para o mundo ocidental, Young menciona o pleno emprego, a incorporação da classe trabalhadora à cidadania, a entrada das mulheres na vida pública e no mercado de trabalho como os componentes de: “(...) uma era de inclusão, afluência e conformismo" (idem, ibid.). Essa era de ouro foi sucedida pela revolução cultural do final da década de 1960, que trouxe o crescimento do individualismo, da diversidade e da desconstrução dos valores tradicionais. Um mundo de certezas foi substituído por outro, de pluralismo, debate, controvérsia e ambigüidade. As certezas da sociedade (família, trabalho, nação, progresso) foram questionadas. Durante a era de ouro, o trabalho e a família compunham juntos um ideal funcionalista: o lugar da produção e o lugar do consumo. Esse mundo de consenso poderia ser caracterizado como inclusivo devido ao acento na assimilação dos trabalhadores das classes populares, das mulheres, dos 
jovens e dos imigrantes. A assimilação implicava a aquisição de direitos legais, políticos e sociais (moradia, trabalho, renda, educação, saúde) e permitiria garantir a incorporação de uma grande maioria da população, apesar da existência de conflitos e contradiçôes que criavam bolsões de extrema miséria e desigualdade (Offe, 1984).

Nessa sociedade caracterizada pelo consenso de valores e pela ordem social incontestável, o desvio era visto como um traço de uma minoria que não possuía valores morais, mas que estaria sujeita à assimilação e à inclusão.

A revolução cultural dos anos de 1960 foi seguida pela crise econômica dos anos de 1970. A certeza e a estabilidade deram lugar à instabilidade e à crise. $\mathrm{Na}$ maior parte dos países desenvolvidos, o aumento dos índices de criminalidade começa nos anos 70 e continua crescendo com o aprofundamento da recessão. Se as décadas de 1960 e 1970 vêem aumentar o individualismo, as décadas de 1980 e 1990 trazem a marca da exclusão social, gerada pela transformação e separação dos mercados de trabalho e pelo aumento do desemprego estrutural.

O movimento da sociedade inclusiva para a sociedade excludente é caracterizado por processos de desagregação tanto na esfera da comunidade (aumento do individualismo), como na esfera do trabalho (transformação dos mercados). A exclusão se dá no mercado de trabalho; na sociedade civil e no sistema de justiça criminal e da segurança privada. Para Young, essa situação tem afetado consideravelmente nossa percepção e reações ao desvio. Na modernidade, o outro desviado aparece como um fenômeno distintivo, de minorias, que contrasta com o consenso da grande maioria com os valores absolutos vigentes. A existência do desvio conforma e confirma os valores da maioria, mais do que os ameaça. Já na modernidade tardia, o outro desviado está em toda parte. Na cidade (Sennett, 1991), o outro não é apenas diferente, mas desviado em potencial. As culturas não somente aparecem como plurais, mas também se apagam, se superpõem e se entrecruzam (Giddens, 1991). A insegurança ontológica cria a necessidade de estabelecer uma base segura, de reafirmar os valores próprios como absolutos morais, de declarar outros grupos como carentes de valores, de ser rígido nos julgamentos, de punir e excluir.

Essas idéias nos fazem pensar nas políticas de educação, principalmente nas políticas de inclusão, desenhadas para integrar alunos que

Educ. Soc., Campinas, vol. 27, n. 96 - Especial, p. 689-715, out. 2006 
Uma análise das condiçôes para a implementação de políticas de educação...

apresentam diferenças ou deficiências. De certa forma, esses alunos também ameaçam e podem ser demonizados por romper a ordem, atentar contra a tão buscada homogeneidade e impedir, assim, uma maior competitividade do sistema. A tensão entre a inclusão, agora no âmbito educativo, e o desempenho em relação ao currículo e às avaliaçôes oficiais é exemplo desse modo particular de ver o outro.

A partir de uma posição crítica do liberalismo, Castel (2003) elabora um quadro de referências centrado na idéia de propriedade. Em diálogo com Haroche, Castel identifica no discurso liberal um indivíduo autônomo e independente das condições sociais e históricas de existência. Estas - principalmente as reguladas pelo Estado - são concebidas como meros entraves ao desenvolvimento humano. Contra essa posição, Castel opõe a hipótese de que o indivíduo não existe como substância. A existência requer "suportes" que permitem a existência. Para Locke, por exemplo, o suporte da existência é a propriedade privada. Esta torna o indivíduo independente, diferentemente da relação de dependência típica do direito feudal (em que todo homem pertencia a outro homem). Isso coloca um grande problema para os não-proprietários: Como farão para existir?

Este problema domina o século XIX e começa a ser resolvido com o desenho de sistemas de proteção, que se afirmam durante o século XX e se constroem a partir do trabalho, oferecendo ao trabalhador impedido uma compensaçãa pela impossibilidade de trabalhar. Esses sistemas se baseiam na proteção e nos direitos sociais que promovem a propriedade social, um novo tipo de propriedade, análoga à propriedade privada, que cumpre a mesma função e garante segurança aos não-proprietários. A noção de propriedade social não é unívoca. É utilizada por pensadores que, desde o século XIX, procuram uma posição intermediária entre o liberalismo puro e a propriedade coletiva. A propriedade social inclui a proteção social, a moradia social, os serviços públicos, um conjunto de bens coletivos providos pela sociedade e postos à disposição dos não-proprietários (Castel \& Haroche, 2003, p. 39). Essa concepção se impôs historicamente e deu origem aos novos sistemas de proteção, nos quais se ancora o chamado Estado-previdência.

Durkheim é um dos sociólogos cuja obra exprime a tomada de consciência sobre as grandes mudanças que abalariam a estrutura social e transformariam os sistemas de proteção na modernidade do mundo 
urbano. Estes se diferenciariam da proteção existente no mundo rural e ligada aos laços familiares e de vizinhança. $\mathrm{Na}$ medida em que um número maior de pessoas se afasta dessa proteção natural, relacionada às formas de sociabilidade primária, aumenta o perigo de anomia, diz Durkheim (1978), a menos que se tomem medidas específicas para evitar isso. O Estado pode e deve intervir nesse processo para manter a coesão social. Essas idéias somente se transformariam em políticas na França, no final do século XIX. Segundo Castel, esses começos foram modestos e o alcance do sistema era restrito à população mais carente e, depois, aos trabalhadores mais pobres. $\mathrm{O}$ sistema se expandiu a partir de 1945, com a extensão da previdência a todos os trabalhadores e ao conjunto da população. Na sociedade "salarial", a propriedade continua sendo um reservatório de vantagens e as diferenças sociais persistem, mas os não-proprietários estão protegidos por um sistema de garantias mínimas que permite alguma participação social. O Estado, neste caso, reduz riscos e conforma uma sociedade de semelhantes, na medida em que os indivíduos se situam num continuum diferenciado de posições.

Esse esquema vale para descrever o sistema de expansão de direitos, que entra em crise na década de 1970 e deve ser atualizado para incorporar fatores, tais como o desemprego maciço e a precariedade que caracterizam as décadas que seguem, embora a concepção básica da sociedade "salarial" continue vigente e permita compreender noções como a de justiça social, a partir da consciência dos indivíduos de serem, ao mesmo tempo, semelhantes e diferentes. Castel recorre à noção de "distinção" de Bourdieu como um bom descritor da "dinâmica social da desigualdade" (Castel \& Haroche, 2003, p. 45). Na sociedade moderna, os indivíduos se situam em grupos sociais mais ou menos definidos por fatores (salário, ocupação, gostos), que os levam a uma identificação com os grupos considerados socialmente superiores e ao distanciamento das categorias consideradas inferiores. Mas, ao formular o principio da desigualdade dos indivíduos, em particular sob a forma de igualdade de oportunidades, as sociedades modernas individualizam a desigualdade: se o jogo é aberto e todo mundo pode competir e ser classificado por mérito, o fracasso é imputável ao próprio indivíduo. Por isso, as desigualdades são vividas não apenas como injustiças, senão, mais dolorosamente, como situações traumatizantes que questionam a própria pessoa. 
Uma análise das condiçôes para a implementação de políticas de educação...

Essas idéias são particularmente claras na análise sociológica dos sistemas educativos. A análise, na perspectiva de Bourdieu, enfoca as condições que determinam o fracasso, ligadas às condições sociais e culturais de base e aos "capitais" (cultural e social) que colaboram para compor o conjunto de recursos de que o individuo dispóe para se desempenhar nas atividades escolares. De uma maneira geral, essa dinâmica acaba distribuindo os indivíduos de acordo com a sua inserção nas diferentes camadas sociais e encaminhando cada um a um destino social condizente com sua origem. Essas idéias podem ser transpostas também para outras esferas de atividade, como a do trabalho.

Em suma, Castel argumenta que a propriedade privada, a partir da constituição dos sistemas previdenciários, não é mais o único suporte para existir positivamente como indivíduo. A propriedade social permite aos não-proprietários acesso à propriedade de si - o que Locke e a tradição do "individualismo positivo" reservavam implicitamente aos proprietários privados (Castel \& Haroche, 2003, p. 50)

Os anos que seguem à crise deflagrada em 1970, entretanto, se caracterizam pela precarização das condições da vida social. Há o enfraquecimento das categorias homogêneas que constituíam a sociedade e das formas de pertença coletiva. $\mathrm{O}$ que é colocado em questão é a própria consistência desses indivíduos que tinham sido incorporados graças à propriedade social. Com o enfraquecimento dos suportes coletivos surge o individuo por carência, que é um individuo desligado do coletivo ou incapaz de inscrever-se em coletivos que ofereçam proteção. Surgem, assim, novas formas de existência dos indivíduos, formas problemáticas e negativas que implicam pouca capacidade de tomar decisóes e de ter iniciativa. Castel descreve, desse modo, duas formas principais de individualidade, com posições intermediárias entre elas. Uma se apóia na posse de bens e de direitos, a outra, na carência desses suportes. São duas maneiras completamente diferentes de existir como individuo.

Apesar de que o foco da sua análise está posto na dinâmica social e nas formas de existência dos indivíduos na sociedade moderna tardia, Castel critica o uso do termo "exclusão". Na sua visão, ninguém está fora do social e o esforço dos cientistas sociais deveria recair sobre as condiçôes que propiciaram as mudanças no processo social, por exemplo, a passagem da integração para a vulnerabilidade e para a "exclusão". Propõe a transversalidade para tentar compreender os conflitos que sacodem a sociedade contemporânea e os processos de constituição 
dos indivíduos. Outra desvantagem do termo "exclusão" é que ele agrupa situações díspares como a dos desempregados, deficientes, jovens, mães solteiras e outras.

É uma maneira puramente negativa de nomear perfis individuais heterogêneos, que não permite analisar a dinâmica que os conduziu até lá. Ao contrário, podemos dizer que na atualidade diferentes tipos de indivíduos são invalidados pela conjuntura econômica e social, e tentar estabelecer os mecanismos de tal invalidação. Ou inclusive dizer que eles têm sido situados em uma posição de inutilidade social, ou de "excedentes", posto que não estão inscritos nas dinâmicas que produzem riqueza e reconhecimento social. (2003, p. 87)

Entretanto, o fato de não ter um lugar reconhecido na sociedade não equivale a não existir socialmente, primeiramente porque a presença dessas pessoas continua a pesar sobre a sociedade e a afetar a vida social. Embora Castel reconheça a proximidade entre a noção de "individualidade negativa" e a de exclusão, insiste na necessidade de trabalhar com as formas e condiçōes da individualidade problemática, de um modo que não seja puramente negativo, concebendo-a como parte integrante da atual configuração da sociedade (ibid., p. 88). Desse ponto de vista, deve-se procurar a construção de novas formas de propriedade social que sejam capazes de controlar e dominar os processos de individualização negativa, característicos da fase do capitalismo que as sociedades modernas atravessam.

Para além das diferenças nos pontos de partida e nos focos de elaboração teórica, na argumentação e na terminologia utilizada, os autores aqui considerados (Hobsbawm, Young e Giddens na Inglaterra, Castel e Bourdieu na França) contribuem para compor a visão de uma sociedade que, nas últimas décadas, tem se caracterizado - dentre outros fatores e em grandes linhas - pelo aumento de tensões decorrentes das mudanças nos processos de produção (que dispensam trabalhadores e deslocam suas sedes de acordo com a conveniência), nos mercados de trabalho (que se flexibilizam e reduzem direitos e garantias dos trabalhadores para atender ao capital), na organização social e no estilo de vida. Nesse contexto, os processos de construção da individualidade são marcados pelo aumento do individualismo e da competição, pela responsabilização do indivíduo pelo seu sucesso ou eventual fracasso, pelo enfraquecimento dos laços de solidariedade coletiva e dos sistemas de proteção social. Os con-

Educ. Soc., Campinas, vol. 27, n. 96 - Especial, p. 689-715, out. 2006 
Uma análise das condiçôes para a implementação de políticas de educação...

flitos sociais violentos protagonizados por jovens descendentes de imigrantes na França, durante o ano de 2005, parecem confirmar essas análises.

\section{A dinâmica inclusão-exclusão no Brasil}

Embora essa descrição da dinâmica social moderna, plena de tensões e contradições, refira-se ao mundo desenvolvido (Estados Unidos e Europa), encontramos, no Brasil, um processo que espelha alguns dos aspectos citados. Um texto recente (Cardoso de Mello \& Novais, 1998) delineia um panorama que admite muitos pontos de coincidência com esse processo. Os autores citam a industrialização, as migrações internas e a urbanização como fatores que fizeram do país, entre 1945 e 1970, uma economia moderna, com padrões de produção e consumo próprios do mundo desenvolvido. $\mathrm{Na}$ década de 1950 , a grande maioria da população era rural e uma minoria morava nas cidades. A década de 1960 assistiu à modernização da agricultura e à migração da população do campo para as cidades, à industrialização e à rápida urbanização. Os protagonistas desses processos foram os migrantes internos, imigrantes estrangeiros e negros urbanos. A família foi a unidade de ascensão social. A expansão se estendeu até a década de 1980 e se caracterizou pela reorganização do Estado, com o crescimento do setor produtivo estatal (siderurgia, petróleo, energia), do sistema financeiro público (BB, BNDE) e do aparelho social (educação, previdência, saúde). Na década de 1980, aumentou a distância social no interior das classes médias. Houve uma queda na remuneração do funcionalismo público, massificação de certas profissões e aumento de emprego no setor de serviços, com baixa remuneração. Alguns dos efeitos desse processo foram: a generalização e a diferenciação do consumo, a segmentação dos mercados e a diferenciação de rendimentos segundo o respectivo mercado de consumo. A dinâmica da economia combinou crescimento, baixos salários, desigualdade, concentração de renda, ampliação rápida dos padrões de consumo modernos, diferenciação e massificação. Os anos de 1990 viram aumentar o desemprego devido à modernização tecnológica e à redução de custos, ao crescimento do trabalho autônomo precário, corte nos gastos sociais, regressão dos direitos trabalhistas, mobilidade social descendente e rebaixamento do padrão de vida, competição exacerbada e aumento da violência. $\mathrm{O}$ estilo de vida mudou e incorporou novos costumes. A tradição foi abando- 
nada em várias esferas da vida: o casamento tornou-se uma relação entre iguais, a educação assumiu características mais permissivas, a religião passou a ser escolhida dentre uma variedade cada vez maior de igrejas e seitas e a família alterou-se em função da vida competitiva, do desemprego, da falta de perspectivas, do consumismo e das drogas (dentre outros).

Nessa perspectiva, os autores coincidem em retratar a sociedade moderna como individualista e competitiva, consumista e narcisista, concluindo que:

Historicamente, a modernidade avança por meio da tensão permanente entre o conjunto de valores mercantis, utilitários, propriamente capitalistas e o outro conjunto de valores. São os valores modernos não mercantis que, corporificados em instituições (democracia de massas, escola republicana, igrejas, família cristã etc.), põem freios ao funcionamento desregulado e socialmente destrutivo do capitalismo. (Cardoso de Mello $\&$ Novais, 1998, p. 607)

Assim, as análises históricas e sociológicas brevemente apresentadas aqui apontam para uma dinâmica de funcionamento que afeta todos os aspectos da vida social: a produção, o consumo, as formas de sociabilidade, o trabalho, a educação, a cultura, a constituição da individualidade. Essa dinâmica produz os processos de inclusão/exclusão (denominação que, após as reflexões anteriores, não parece totalmente adequada) que serão examinados aqui no caso particular das políticas e práticas educativas.

O objetivo deste texto é argumentar em favor de uma visão que integre a análise dessas políticas e práticas a uma análise do movimento social mais amplo em que se inserem. Do nosso ponto de vista, as dificuldades que se apresentam na implementação dessas políticas somente podem ser compreendidas a partir da consideração da dinâmica social na qual estão inseridas. $\mathrm{O}$ exame da política de inclusão de alunos com necessidades especiais no ensino regular é particularmente interessante, porque, neste caso, as diferenças entre indivíduos e grupos entram em conflito imediato com os modos de funcionamento do sistema escolar, evidenciando as tensões que perpassam o campo da educação.

\section{As políticas de educação inclusiva na Inglaterra}

Assim como no Brasil, durante boa parte do século XX, as concepções que norteavam a educação especial no Reino Unido da Ingla-

Educ. Soc., Campinas, vol. 27, n. 96 - Especial, p. 689-715, out. 2006 
Uma análise das condiçôes para a implementação de políticas de educação...

terra enfatizavam os aspectos médicos e as características individuais das pessoas com necessidades especiais. Embora uma parte dessas pessoas fosse educada na rede regular, a provisão de educação especial era considerada uma atribuição das escolas ou serviços especiais.

No final da década de 1970, o documento conhecido como Relatório Warnock (Warnock Report, 1978) emerge na cena educacional do Reino Unido e marca as concepçóes sobre necessidades especiais e inclusão escolar. Beveridge (1999) destaca a importância desse Relatório para a disseminação do conceito de necessidades especiais atualmente utilizado. O Relatório foi o produto do trabalho de um comitê governamental, cuja missão era investigar e fazer recomendaçôes relacionadas ao provimento de educação especial. Este documento é tido como um grande avanço no pensamento oficial. Um dos seus méritos reside na compreensão das necessidades especiais como um assunto relacionado à educação em geral e não como uma questão a ser tratada por especialistas.

O Relatório Warnock chamou a atenção para o grande número de crianças em escolas comuns que, em algum momento de sua trajetória, experimentam dificuldades. Entendia as necessidades educacionais como um continuum, no qual deveriam situar-se todos os alunos. Nessa perspectiva, a educação especial era definida como qualquer forma de ajuda adicional destinada à superação das dificuldades dos alunos (Warnock Report, 1978, parágrafo 1.3, apud Beveridge, 1999).

O Relatório destaca a necessidade de acabar com as categorias potencialmente estigmatizantes para as crianças, de reconhecer a grande variabilidade das necessidades dos alunos, mesmo considerando-se cada deficiência por separado e, ainda, afirma que critérios médicos não são necessariamente úteis e produtivos para a educação. A partir dessas premissas, propôs a descrição das dificuldades como: leves, moderadas, severas ou específicas. Embora, dessa forma, o relatório assentasse as bases de uma nova categorização, ele contribuiu para a mudança na concepção das dificuldades escolares e das necessidades educativas especiais. Sem negar a importância dos fatores individuais, enfatizou a interação da criança e o contexto educacional e promoveu a compreensão das necessidades educacionais especiais como uma defasagem entre o conhecimento, as competências e experiências que a criança traz para a situação de aprendizagem e as demandas a que ela está sujeita (Warnock Report, 1978, parágrafo 3.19, apud Beveridge, 1999). 
Antes, a educação especial podia ser concebida como um sistema diferenciado da educação regular. Os alunos com dificuldades eram destinados a outros serviços e instituições. Após o Relatório, a responsabilidade da educação para os alunos com necessidades especiais recaiu nas autoridades escolares e nos professores.

Dentre as recomendações do Relatório estava a de que a provisão de educação especial fosse vista mais como "adicional e suplementar", do que "separada e alternativa" ao ensino regular. Para a maioria dos alunos, ela deveria ocorrer, portanto, na sala de aula comum, com apoio, se fosse necessário. Foi proposto, também, um sistema para identificar e avaliar as necessidades educacionais das crianças. Os pais foram considerados como participantes-chave no processo de tomada de decisōes.

Muitas das recomendações do Relatório Warnock estão presentes nos documentos oficiais posteriores. A Education Act, de 1981, expressa a preocupação com a definição das necessidades educacionais especiais e com a atuação das escolas regulares. Também aborda a avaliação das necessidades especiais e o direito dos pais de tomar parte no processo decisório. Apesar deste documento ter sido substituído por legislação mais recente, suas principais diretrizes continuam vigentes. Em 1988, o documento Education Reform Act afirmou a necessidade de um currículo amplo e equilibrado que pudesse ser aplicado a todos os alunos, inclusive àqueles com necessidades educativas especiais. $\mathrm{O}$ documento permite a suspensão temporária do currículo nacional (de até um ano) e a não aplicação no caso de crianças com necessidades especiais. Beveridge (1999, p. 23) comenta, entretanto, que em geral o currículo nacional tem sido aplicado na maioria dos casos. O documento determina também que a administração do orçamento retorne às escolas e que a alocação de verbas seja atrelada ao número de alunos matriculados. As escolas se transformam, assim, em competidoras que devem se esforçar em manter elevados níveis de matriculas. A competição ocorre no terreno do desempenho em relação ao currículo nacional. A presença de alunos com necessidades especiais nas escolas significa nesse contexto - um desempenho mais baixo nas avaliaçóes. Por outro lado, é previsto um financiamento adicional para atender esses alunos. As medidas preconizadas pelo documento de 1988 devem ser compreendidas no contexto das políticas do governo Thatcher, com as suas inclinações neoliberais e mercadológicas. 
Uma análise das condiçôes para a implementação de políticas de educação...

Do ponto de vista dos alunos com necessidades especiais, o documento foi benéfico porque garantiu o acesso a uma gama mais ampla de experiências de aprendizagem. Vários autores referem preocupação com o tipo de atendimento oferecido, já que houve, no período, uma redução de pessoal de suporte e uma diminuição das iniciativas de educação inclusiva (Clark et al., 1997), um maior número de encaminhamentos (Davie, 1996) e um aumento da exclusão permanente de alunos (Garner, 1993; Parsons \& Howlett, 1996).

Os documentos que sucederam aos de 1981 e 1988 foram: Education Act (1993) e, posteriormente, Education Act (1996). O Code of Practice era um guia prático para autoridades e escolas. A nova legislação enfatizava o atendimento educacional em escolas comuns. Estas deveriam ter políticas para o atendimento das necessidades especiais, informar os pais e relatar a eficácia das políticas. Elas deveriam, ainda, nomear um coordenador (Special Needs Coordinator - SENCO) na escola. O cargo é visto como chave na implementação de políticas inclusivas. Em 1997, o documento Excellence for all children: meeting special educational needs recomendava fortemente os princípios da inclusão com base em argumentos morais, sociais e educacionais. Abordava também as expectativas em relação ao desempenho dos alunos e a necessidade de dar apoio e suporte aos pais, investindo recursos na intervenção precoce e na prevenção. Propunha também a promoção da colaboração entre as agências envolvidas na provisão de educação e destacava a necessidade de melhorar a formação de profissionais.

Os documentos mais recentes que regem as escolas do Reino Unido datam de 2001. O novo código de prática (Special Educational Needs Code of Practice, 2001) é, como o anterior, um guia para a ação cujos objetivos são: que os alunos com necessidades especiais atinjam seu potencial, sejam incluídos nas escolas de suas comunidades e façam uma transição bem-sucedida para a vida adulta. As crianças com necessidades especiais devem ter as suas necessidades satisfeitas, o que representa uma mudança importante em relação a documentos anteriores, que recomendavam, mas não impunham às escolas a obrigação de assumir essa responsabilidade. O documento aborda também a necessidade de se estabelecer parcerias com os pais dos alunos, o envolvimento dos próprios alunos como participantes do processo e a identificação, avaliação e atendimento das necessidades especiais na educação infantil, primária e secundária (3-14 anos). 
O código reafirma o direito à educação em escolas comuns e atribui às autoridades escolares responsabilidade no provimento de serviços de informação e aconselhamento aos pais e na solicitação de avaliações diagnósticas das crianças.

Outro documento, ainda, o Special Educational Needs and Disability Act (SENDA, 2001) faz emendas a documentos anteriores e proíbe a discriminação com base na deficiência em estabelecimentos educacionais. Fortalece o direito de crianças com necessidades especiais à educação em escolas comuns, obriga as autoridades a informar e a disponibilizar aconselhamento para os pais e a nomear pessoas independentes no caso de disputas. As escolas devem, também, fazer ajustes razoáveis para permitir a entrada do aluno em condiçóes adequadas. As autoridades devem elaborar estratégias para a acessibilidade, enquanto as escolas devem elaborar planos para aprimorar o acesso à educação (melhorias no acesso ao currículo, estrutura física e provisão de informação em diferentes formatos para atender diferentes necessidades). As autoridades escolares devem informar anualmente sobre o trabalho realizado. $\mathrm{O}$ documento especifica, ainda, as responsabilidades das instituições de educação continuada e superior em relação aos alunos com necessidades especiais.

A análise dos documentos citados revela que, no Reino Unido, um debate mais amplo sobre as necessidades especiais teve lugar no final da década de 1970, como atesta o Relatório Warnock. O debate foi ampliado na década seguinte, com a abordagem de novos aspectos. A afirmação do direito à educação foi traduzida, inicialmente, em uma política que enfatizava a educabilidade de todas as crianças, mas não exigia que o sistema escolar as atendesse. Durante a década seguinte, as "necessidades especiais" adquiriram novos sentidos e a rede comum (ao invés das instituições especializadas) passou a responder pela provisão de educação especial. Entretanto, como apontam vários autores (Daniels \& Anghileri, 1995), a legislação, por um lado, afirma o direito à educação, mas, por outro, cria mecanismos que permitem a permanência do status quo, ao sugerir que as escolas "façam alterações que sejam razoáveis", por exemplo. A indeterminação e ausência de regras claras se expressam em uma formulação no mínimo vaga e ambígua.

No final da década de 1980, emerge a questão do currículo: as oportunidades de acesso a experiências de aprendizagem variadas devem ser incrementadas e o currículo deve ser amplo e equilibrado, de 
Uma análise das condiçôes para a implementação de políticas de educação...

modo que possa ser utilizado com todos os alunos. As escolas, entretanto, podem não utilizar o currículo oficial nos casos em que considerem isso necessário. Nesse momento, implementa-se, também, uma mudança de financiamento e as escolas passam a administrar o orçamento que inclui verbas específicas para o atendimento das necessidades especiais. A cooperação entre escolas ou serviços, entretanto, é praticamente desencorajada por essa política de cunho mercadológico, que concebe os agentes educacionais como regulados pela oferta e demanda e pela competição entre os prestadores de serviços (Daniels \& Anghileri, 1995). Rouse e Florian (1997) argumentam que houve, nesse período, uma mudança de legislação e políticas que se baseavam nos princípios da eqüidade, no progresso social e no altruísmo. A nova legislação assenta-se na filosofia do mercado, nos princípios de excelência acadêmica, escolha e competição. Nesse contexto, os alunos com deficiências ou necessidades especiais são particularmente vulneráveis. A tarefa das escolas de tornarem-se inclusivas fica mais complicada, porque contradiz a tendência das reformas educacionais.

$\mathrm{Na}$ década de 1990, os documentos mantêm as tendências já explicitadas e destacam o atendimento preferencial das necessidades especiais em escolas comuns. As escolas são responsáveis pela formulação de projetos de atendimento, pela informação aos pais e pela comunicação dos resultados. Por fim, os documentos mais recentes, de 2001, enfatizam o atendimento centrado nos alunos, a inclusão e a responsabilidade das escolas no provimento de educação para todos, assim como a necessidade de informar e de estabelecer parcerias com os pais.

Há várias maneiras de ler a legislação e os documentos oficiais das últimas décadas. Uma leitura possível poderia identificar uma certa progressão, definida pela emergência sucessiva de novas questôes e mudanças de concepção, cujas razões e motivações parecem concatenar-se naturalmente no sentido de um desenvolvimento crescente. A leitura em que nos empenhamos tenta integrar o contexto social e político à análise, incorpora elementos históricos e nos leva a interpretar essas mudanças como parte de uma tendência mais ampla, que afeta outras esferas da vida e se manifesta, também, no campo da reforma educacional. Enquanto os documentos abordam, cada vez mais detalhadamente, os procedimentos destinados à implementação das políticas inclusivas e tentam resolver os problemas práticos, cresce a tensão entre essas prescriçõos e a dinâmica geral do sistema educativo, que é regida 
por uma lógica bastante diferente, tendendo à seletividade e à eficiência na classificação e distribuição dos alunos. Da mesma forma em que o sistema educativo, malgrado os parâmetros curriculares, reformas e projetos de aceleração, não consegue educar todas as crianças, ele não dá conta tampouco de oferecer um ensino relevante para aquelas com necessidades educativas especiais.

\section{As políticas de educação inclusiva no Brasil}

No Brasil, apenas em 1988, com a promulgação da Constituição Federal, é oficializado um dos princípios inclusivos: o de que os portadores de deficiências devem ser educados preferencialmente na rede regular de ensino. A Constituição afirma, também, que a educação é um direito público e subjetivo e menciona o direito de acesso aos "níveis mais elevados do ensino, da pesquisa e da criação artística, segundo a capacidade de cada um" (art. 208). O artigo 227 dispóe, por sua vez, sobre a criação de programas de prevenção, atendimento especializado, integração social, treinamento para o trabalho e remoção de barreiras arquitetônicas.

Haveria de passar mais uma década, ainda, até que, em 1996, a Lei de Diretrizes e Bases da Educação Nacional (LDBEN) incorporasse a noção de que o sistema educacional deve estar centrado nos alunos, quaisquer que sejam as suas características. A Lei define a educação especial como educação escolar e reafirma o provimento preferencial na rede regular (at. 58), além de prescrever a oferta de serviços de apoio especializado na própria escola. Mantém o atendimento em classes, escolas ou serviços especializados "sempre que, em função de condições específicas dos alunos, não for possível a integração nas classes comuns". Estabelece, também, que a oferta de educação especial deve ser iniciada durante a educação infantil (0-6 anos).

Os documentos oficiais que anteriormente regulamentavam a educação especial tinham como pressuposto o direito à educação e se ocupavam da organização dos serviços de apoio, mas revelavam uma concepção centrada no próprio indivíduo, considerado, em última instância, responsável pelas suas dificuldades (Laplane, 2004a). Apesar disso, é preciso lembrar que a Lei de Diretrizes e Bases de 1961 menciona, entre os seus objetivos, o de integrar as crianças excepcionais à sociedade. 
Uma análise das condiçôes para a implementação de políticas de educação...

A Lei de 1996 estabelece, no seu artigo 59, que os sistemas de ensino devem se organizar para assegurar aos alunos com necessidades especiais "currículos, métodos, técnicas, recursos educativos e organização específicos, para atender as suas necessidades". A Lei menciona a terminalidade específica ou a aceleração, segundo o caso, para os alunos que não atingirem o nível exigido para a conclusão do ensino fundamental ou para os que o atingirem antes do previsto. Os sistemas de ensino devem oferecer aos alunos acesso a professores com especialização adequada para atendimento especializado e a professores capacitados para trabalhar na sua integração na rede regular. Deve ser oferecida, também, educação especial para o trabalho ${ }^{1}$ e acesso igualitário aos benefícios dos programas sociais suplementares disponíveis para o ensino regular. No artigo 60, consta que os órgãos normativos dos sistemas de ensino estabelecerão critérios para caracterizar as instituiçōes (privadas, sem fins lucrativos, especializadas e com atuação exclusiva em educação especial), que poderão receber apoio técnico e financeiro do poder público. Enfatiza, entretanto, que a alternativa preferencial será a de ampliar o atendimento na própria rede pública.

O Plano Nacional de Educação (2001) afirma, entre outras metas: o desenvolvimento e a ampliação de programas educacionais em todos os municípios, o trabalho em parceria com as áreas de saúde e assistência social, a realização de ações preventivas nas áreas visual e auditiva, a generalização do atendimento aos alunos na educação infantil e no ensino fundamental, o atendimento na rede regular de ensino ou em classes e escolas especiais, a educação continuada dos professores em exercício e a formação de professores em instituições de ensino superior. $\mathrm{O}$ documento tem sido criticado por pesquisadores e profissionais da área, dentre outros motivos, por retirar a ênfase da provisão de educação preferencial em classe comum e ampliar a possibilidade de atendimento em escola ou classe especial. A crítica deve ser entendida no contexto de uma tendência à privatização das vagas na educação especial, verificada nos dados de 2001 (que se mantêm no ano de 2004), segundo os quais mais de $60 \%$ das vagas estavam concentradas na rede particular (Ferreira \& Ferreira, 2004).

Em 2001, as Diretrizes para a Educação Especial mencionam, pela primeira vez, a inclusão. O documento cita a legislação anterior como base para a sua elaboração e dá destaque à Declaração de Salamanca (1994), enquanto fonte de inspiração filosófica. Como lem- 
bra Kassar (2004), a idéia norteadora da Declaração é a de que todas as escolas deveriam acomodar todas as crianças e encontrar uma maneira de educá-las com êxito. Essa idéia impulsionou a difusão do termo "inclusão" e, também, popularizou a noção de que todas as crianças devem ser educadas no mesmo ambiente.

Por outro lado, a nossa análise de alguns aspectos da Declaração, realizada em um texto anterior (Laplane, 2004a), revelou o apagamento da dimensão política, a persistência da visão ingênua que atribui à educação o poder de mudar, sozinha, a sociedade e uma certa tendência à prescrição. A leitura das Diretrizes permite identificar, em alguns momentos, a persistência dessas características. Vejamos a sua primeira definição de inclusão: (...) a garantia a todos do acesso contínuo ao espaço comum da vida em sociedade, sociedade essa que deve estar orientada por relaçôes de acolhimento à diversidade humana, de aceitação das diferenças individuais, de esforço coletivo na equiparação de oportunidades de desenvolvimento, com qualidade, em todas as dimensôes da vida. (2004, p. 7)

A definição remete a um conceito amplo de inclusão, mas a afirmação de que a sociedade "deve estar orientada por relações de acolhimento à diversidade humana" apaga o fato de que a sociedade não se caracteriza por essa orientação e simplifica, na forma de uma prescrição ingênua, um complexo conjunto de relações que, como vimos, diz respeito a fatores sociais, econômicos, políticos, culturais, étnicos, religiosos etc. (Laplane, 2004b).

Além disso, persiste no documento a menção ao objetivo de "promover o desenvolvimento das potencialidades dos educandos que apresentam necessidades educacionais especiais, em todas as etapas e modalidades da educação básica", o que remete à concepção que, ainda, torna o aluno culpado do seu próprio fracasso.

As Diretrizes destacam o surgimento de uma nova mentalidade (Brasil, 2001, p. 8) e assumem como princípios: o direito à dignidade, à busca de identidade e o exercício da cidadania (p. 9). A noção de inclusão é objeto de nova elaboração, enfatizando-se que ela não é um mero mecanismo, mas requer a revisão de concepções e paradigmas ( $\mathrm{p}$. 12). A discussão interna sobre a função social da escola, a construção de um projeto pedagógico que privilegie práticas heterogêneas e o protagonismo dos professores são vistos como chaves para a inclusão. Os sistemas escolares são instados a assegurar a matrícula de todos os alunos e a organizar-se para atendê-los. Devem oferecer os recursos pe- 
Uma análise das condiçôes para a implementação de políticas de educação...

dagógicos necessários e capacitar profissionais para atender às demandas dos alunos (p. 12). A política inclusiva exige a intensificação da formação de recursos humanos, a garantia de recursos financeiros e de apoio pedagógico e o exercício da descentralização do poder. Deverão ser criados sistemas de informação que permitam a avaliação das condições reais para a inclusão e o conhecimento da demanda, assim como a identificação, análise, divulgação e intercâmbio de experiências educacionais inclusivas (p. 13). A capacitação dos professores e a flexibilização do currículo são fatores que colaborarão para o sucesso da política inclusiva. No que se refere aos aspectos pedagógicos, as escolas devem avaliar os alunos e prover serviços e apoios requeridos. $\mathrm{O}$ atendimento fora da sala de aula regular será considerado como recurso extraordinário e temporário, a não ser nos casos que necessitem de atendimento especial contínuo, que poderão ser encaminhados para escolas especiais (públicas ou privadas).

No âmbito administrativo, as Diretrizes afirmam a alocação de recursos materiais e humanos para atender às demandas tanto nos aspectos físicos, relacionados às barreiras arquitetônicas, como nos aspectos da comunicação e os mais estreitamente ligados ao ensino e à aprendizagem. As estratégias de comunicação e ação comunitária são consideradas como formas de reafirmar o compromisso político com a inclusão.

As necessidades especiais são caracterizadas, no documento, como aquelas que decorrem de dificuldades acentuadas de aprendizagem com ou sem causa orgânica, dificuldades de comunicação e altas habilidades. Com relação a essa definição, a análise de Kassar (2004) levanta a questão de um possível retorno aos tempos em que um grande número de crianças com trajetórias de insucesso, devidas a causas as mais variadas, eram mantidas em classes especiais que não propiciavam o progresso acadêmico e acabavam sendo excluídas da escola.

Por fim, as Diretrizes definem as formas de atendimento: em classe regular, com ou sem apoio, em classe ou escola especial. $\mathrm{O}$ documento avança, também, na descrição das açōes necessárias para adaptar o currículo e discorre sobre a terminalidade e sobre a avaliação.

No início de 2004, a Secretaria de Educação Especial do Ministério de Educação lançou a série Educação Inclusiva, um conjunto de documentos destinados a promover a implementação da política de inclusão escolar. A série é composta de quatro documentos que abordam os aspectos filosóficos da inclusão, o papel dos municípios, da escola e 
da família. O primeiro deles assume como ponto de partida a Declaração Universal dos Direitos Humanos, os princípios de liberdade, igualdade e fraternidade e o respeito à diversidade como uma conseqüência dos anteriores.

A idéia de uma sociedade inclusiva fundamenta-se numa filosofia que reconhece e valoriza a diversidade, como característica inerente à constituição de qualquer sociedade. Partindo desse princípio e tendo como horizonte o cenário ético dos Direitos Humanos, afirma a garantia de acesso e a participação de todos, independentemente das peculiaridades de cada indivíduo e/ou grupo social (Brasil, 2004, p. 8).

O documento cita também a Declaração de Salamanca (1994) e o documento resultante da Convenção de Guatemala (1999) como documentos internacionais que fundamentam o Programa. A legislação nacional citada inclui a Constituição Federal (1988), o Estatuto da Criança e do Adolescente (1990), a Lei de Diretrizes e Bases (1996), o Decreto 3.298 (1999), o Plano Nacional de Educação (2001), o Decreto 3.956 (2001) e as Diretrizes Nacionais para a Educação Especial na Educação Básica (2001), além de um conjunto de documentos norteadores da educação que orientam a ação inclusiva nos diferentes níveis e modalidades do sistema de ensino.

O documento sobre a escola destaca que ela deve organizar-se "de forma a garantir que cada ação pedagógica resulte em uma contribuição para o processo de aprendizagem de cada aluno" (Brasil, 2004, p. 9). Afirma que:

Escola inclusiva é aquela que garante a qualidade de ensino educacional a cada um de seus alunos, reconhecendo a cada um de acordo com suas potencialidades e necessidades.

Assim, uma escola somente poderá ser considerada inclusiva quando estiver organizada para favorecer a cada aluno, independentemente de etnia, sexo, idade, deficiência, condição social ou qualquer outra situação. Um ensino significativo é aquele que garante o acesso ao conjunto sistematizado de conhecimentos como recursos a serem mobilizados. (p. 9)

A definição é ampla e abrange não apenas as necessidades especiais, mas toda a variedade e diversidade da população escolar. O documento afirma ainda que o aluno é o foco da ação educacional, a qual deve visar à aprendizagem e à construção de competências que o habi- 
Uma análise das condiçôes para a implementação de políticas de educação...

litem para a cidadania. A escola deve conhecer cada aluno, respeitar suas potencialidades e responder às suas necessidades com qualidade pedagógica. Da escola inclusiva participam todos os atores do cenário educacional: gestores, professores, familiares e membros da comunidade em que cada aluno vive.

O projeto pedagógico é visto como instrumento de mudança que irá explicitar os objetivos e métodos das ações pedagógicas a serem implementadas. É o mediador entre a política do município e a população e é construído de forma coletiva, envolvendo o planejamento participativo e o aperfeiçoamento constante. $\mathrm{O}$ conselho de escola, assim como o diretor e o coordenador pedagógico, têm também importantes funções no desenvolvimento e regulamentação de procedimentos para identificar e atender as necessidades dos alunos, realizar adequaçóes curriculares e garantir a acessibilidade física e o acesso ao conhecimento, fornecendo os recursos materiais e humanos que se fizerem necessários (professor de Braille, professor de LIBRAS, material adaptado para baixa visão, computadores com softwares especiais etc.). Salienta, também, que o apoio para o professor deve ser previsto pela gestão da escola.

O documento revela uma concepção ampla de inclusão e uma preocupação com a prática. Procura abordar os aspectos que, na experiência das escolas, têm sido apontados como problemáticos: a identificação das necessidades especiais e a elaboração de estratégias de atendimento, a disponibilidade de recursos para implementar a flexibilização curricular e o apoio ao professor, situação que, apesar da existência de salas de recursos e professores itinerantes, segundo o modelo adotado pelo sistema de ensino, até agora não tinha sido prevista de forma sistemática e, sobretudo, eficaz.

A leitura cronológica dos documentos indica mudanças de posição, as quais incorporam as idéias que circulam nos documentos e foros internacionais. As políticas são cada vez mais detalhadas e explicitadas em documentos que tratam de questões e relações específicas à implementação das políticas de inclusão nas escolas. Malgrado as enormes diferenças entre os dois países (sociais, econômicas, políticas e culturais), que se estendem aos respectivos sistemas de ensino (que envolvem histórias de formação totalmente distintas), emerge, com certa força, na leitura, um traço que aproxima as políticas educativas no Brasil e no Reino Unido, ao menos no que se refere às políticas de inclusão: a afirmação dos prin- 
cípios inclusivos e o tratamento da questão como um problema prático, de implementação, que deve ser resolvido por meio das medidas pontuais contidas na legislação e nos documentos oficiais.

\section{Considerações finais}

Na chegada ao Reino Unido, uma das sensaçôes mais fortes, ao tomar contato com o debate educacional (sempre em pauta, seja na mídia, no ambiente político ou acadêmico), foi a de que os problemas da educação, apesar das imensas diferenças históricas, sociais, econômicas e culturais que separam os dois países, eram muito parecidos aos do Brasil. Apesar do tempo transcorrido e do maior conhecimento que hoje detenho sobre essas questôes, essa primeira impressão não se desfez.

A dinâmica social mais ampla que condiciona a implementação de políticas públicas parece ser a principal responsável por essa semelhança. A tentativa de analisar a inclusão e a exclusão como dimensões da dinâmica social e não como meros mecanismos levou-me a examinar os sistemas de educação imersos no processo que, na visão de alguns historiadores, como Hobsbawm, tem gerado uma sociedade de características excludentes para a maioria da população. Esse processo, iniciado nos anos de 1970, pode ser contrastado com o quadro social de pós-guerra, caracterizado pela inclusão de grandes e diversos contingentes de pessoas à economia, à educação e ao bem estar. A sociedade que emerge da crise caracteriza-se por mudanças dramáticas nos processos e no mercado de trabalho, pelo aumento do desemprego estrutural e pela mudança nos estilos de vida, com aumento do individualismo, competitividade e consumismo (dentre outros), acompanhados do afrouxamento dos laços de solidariedade social. É uma sociedade na qual as diferenças se tornam irredutíveis, onde o consenso e a relativa homogeneidade deixam lugar para a diversidade e para a diferença. Nesse contexto, os sistemas educativos têm que cumprir suas múltiplas e, às vezes, contraditórias metas.

As semelhanças encontradas entre os sistemas de educação de ambos os países deixam de surpreender-nos quando lembramos as análises de Bourdieu sobre o sistema educacional francês e a sua possível vigência para analisar outras realidades. Tomemos, por exemplo, um fator interno aos sistemas de ensino, como a heterogeneidade constitutiva 
Uma análise das condiçôes para a implementação de políticas de educação...

da população escolar, que pode ser identificada em ambos os contextos. A heterogeneidade assume formas diferentes nos dois países. $\mathrm{O}$ componente multicultural, forte em ambos, configura-se de maneiras muito diferentes. No caso do Reino Unido, as comunidades de imigrantes de diferentes etnias, países, culturas, línguas e religiões, que chegaram ao país em diferentes épocas (e continuam chegando), colocam um grande desafio ao sistema educativo, regido por um currículo nacional que encontra resistência ou ausência de requisitos mínimos para ser implementado. No caso do Brasil, o multiculturalismo é inerente à própria conformação da Nação, que desde a sua criação envolveu europeus, nativos e afrodescendentes. Em ambos os casos, a influência dos fatores socioeconômicos é grande e afeta a capacidade dos sistemas educativos de prover educação para todos.

As políticas de educação inclusiva constituem um exemplo do modo como as tendências e os traços da sociedade antes citados criam condições específicas de funcionamento dos sistemas de educação. As políticas inclusivas estão baseadas em princípios morais e políticos estabelecidos nos documentos nacionais e internacionais e na legislação, tanto nos países desenvolvidos como nos países em desenvolvimento: a educação de qualidade tem se tornado um direito humano inquestionável e os países têm formulado políticas e leis que, aparentemente, visam a garanti-la. As políticas, como vimos, muitas vezes contêm prescrições detalhadas sobre vários assuntos (acessibilidade, flexibilização do currículo, suporte para professores e alunos etc.). Entretanto, algumas questóes permanecem: Por que é tão difícil implementar políticas de educação inclusiva? Por que é tão larga a brecha entre as políticas e as práticas?

O objetivo de tornar a educação acessível a todos os membros de uma comunidade (como explicitado na maioria dos documentos oficiais) colide com a rigidez dos tempos, a tendência à homogeneização e a necessidade de obter um alto desempenho (medidas da qualidade). A contradição no âmbito educacional remete às condições sociais mais amplas e à tendência excludente da dinâmica social.

O grande esforço de elaboração conceitual e de reflexão sobre as práticas e seus efeitos e impactos na constituição dos indivíduos, nas suas trajetórias, expectativas e possibilidades de sucesso ou fracasso, ajuda a dimensionar a dificuldade da empreitada. Prover uma educação de qualidade para todos, no quadro do sistema de educação que possuímos, 
constituído historicamente de um modo particular, que privilegia qualidades que não necessariamente ensinam, envolve certas limitações. Do meu ponto de vista, a compreensão dessa dinâmica é importante não apenas no que se refere à teoria, mas também às práticas. A possibilidade de analisar as condiçôes de funcionamento do sistema educativo, seu papel na reprodução e divisão da sociedade em grupos mais e menos privilegiados, é fundamental para compreender o sentido da prática educativa, de um modo geral, e os sentidos particulares das políticas e ações relacionadas ao ensino. Ela deve permitir aos educadores avaliar as possibilidades de sucesso e estabelecer as prioridades e estratégias a serem utilizadas em cada situação. Isto é particularmente importante no que diz respeito às questôes que resistem às tentativas de explicação, às políticas formuladas e às práticas implementadas, como é o caso da inclusão.

As propostas centradas nos aspectos práticos da inclusão (a formação, o repertório de ensino, os sentimentos dos professores em relação aos alunos com necessidades especiais) apenas terão chances de sucesso se inseridas numa análise ampla da escola como instituição atravessada por conflitos e demandas contraditórios entre si. Um exemplo disso é a oposição entre os traços de seletividade do sistema, por um lado, e a necessidade de que todos aprendam, por outro. A política inclusiva promove uma escola que se organiza para favorecer cada aluno, independentemente das suas habilidades, condições etc. A verdade é que ela deve organizar-se para favorecer a aprendizagem de cada aluno, mas dentro de parâmetros e limites bastante rígidos, que tornam a tarefa difícil e complexa.

Entendo que enfocar a magnitude dessa tarefa, a sua complexidade e os seus limites e possibilidades é mais produtivo no terreno das práticas educativas do que difundir um discurso ingenuamente otimista, que proclama a celebração da diversidade sem oferecer ao educador os elementos necessários para situar-se na realidade que irá enfrentar.

Políticas e práticas estão imersas num contexto que, a cada momento, redefine as relações entre elas. Esse contexto envolve a dimensão cultural, ideológica, os valores, as relações de poder, dentre outras. Do ponto de vista de quem está situado no lugar da prática, essas relações não são muito claras e há uma tendência a conceber de forma separada a dimensão política e a da prática. Quando os profissionais se voltam unicamente para os aspectos práticos, perdem de vista o quadro 
Uma análise das condiçôes para a implementação de políticas de educação...

geral e insistem em procurar e aplicar métodos, técnicas ou atividades na expectativa de que resolvam os problemas. A visão estreita de educação como ensino-aprendizagem tem seu preço: impede que sucessos e fracassos sejam analisados no quadro das possibilidades criadas pelas condições em que essas práticas ocorrem.

Para finalizar, gostaria de registrar a minha concordância com as palavras de Corbett (2001), quando afirma que: “(...) a educação inclusiva diz respeito à qualidade da educação comum e não à educação especial". De alguma forma, as perguntas que percorrem este estudo - resultado de leituras, conversas, observações e reflexões sobre o papel da educação nas sociedades contemporâneas - dizem respeito às relações entre a educação e a sociedade e aos modos de funcionamento dos sistemas educativos, às suas funções, problemas e possibilidades de contribuir para uma sociedade mais justa.

Recebido em março de 2006 e aprovado em junho de 2006.

Nota

1. A formulação da Lei com relação ao trabalho é digna de comentário: "IV - educação especial para o trabalho, visando a sua efetiva integração na vida em sociedade, inclusive condiçôes adequadas para os que não revelarem capacidade de inserção no trabalho competitivo, mediante articulação com os órgãos oficiais afins, bem como para aqueles que apresentam uma habilidade superior nas áreas artística, intelectual ou psicomotora". A menção ao trabalho competitivo, por oposição a um tipo de trabalho que não é competitivo, sugere a necessidade de uma reflexão mais profunda sobre o estatuto do trabalho na sociedade e as formas de participação de diferentes grupos sociais. Foge aos objetivos desse texto avançar nessa direção, mas cabe aqui abrir a questão e dar crédito à professora Gilberta Jannuzzi pela sua insistência em incentivar a importância de abordar esta questão.

Referências bibliográficas

BEVERIDGE, S. Special educational needs in schools. London: Routledge, 1999.

BRASIL. Constituição (1988). Constituição da Republica Federativa do Brasil. Brasília, DF: Senado, 1998.

BRASIL. Coordenadoria Nacional para Integração da Pessoa Portadora de Deficiência. Declaração de Salamanca e linha de ação sobre necessidades educativas especiais. Brasília, DF: CORDE, 1994. 
BRASIL. Instituto Nacional de Pesquisas Educacionais Anísio Teixeira. Sinopse estatística da educação básica: censo escolar 2004. Brasília, DF: O Instituto, 2004.

BRASIL. Lei n. 8.069, de 13 de julho de 1990. Dispóe sobre o Estatuto da Criança e do Adolescente e dá outras providências. Diário Oficial da União, Brasília, DF, 16 jul. 1990. Seção 1, p. 13563-577.

BRASIL. Lei n. 9.394, de 20 de dezembro de 1996. Estabelece as diretrizes e bases da educação nacional. Diário Oficial da União, Brasília, DF, 23 dez. 1996. p. 27894.

BRASIL. Lei n. 10.172, de 9 de janeiro de 2001. Aprova o Plano Nacional de Educação e dá outras providências. Diário Oficial da União, Brasília, DF, 10 jan. 2001.

BRASIL. Ministério da Educação. Educação para todos. Avaliação: políticas e programas governamentais de educação especial. Brasília, DF: MEC/SEESP, 2000.

BRASIL. Ministério da Educação. Resolução CNE/CEB n. 2, de 11/09/ 2001. Institui Diretrizes Nacionais para a Educação Especial na Educação Básica. Diário Oficial da União, Brasília, DF, 14 set. 2001. Seção 1-E, p. 39-40.

CARDOSO DE MELLO, J.M.; NOVAIS, F.A. Capitalismo tardio e sociabilidade moderna. In: NovaIs, F.A.; SChWArCs, L.M. (Org.). História da vida privada no Brasil. São Paulo: Cia das Letras, 1998.

CASTEL, R. As metamorfoses da questão social: uma crônica do salário. Petrópolis: Vozes, 1998.

CASTEL, R.; HAROCHE, C. Propiedad privada, propiedad social, propiedad de si mismo. Rosario: Homo Sapiens, 2003.

CLARK, C. et al. New directions in special needs: innovations in mainstream schools. London: Cassell, 1997.

CORBETT, J. Supporting inclusive education: a connective pedagogy. London: Routledge, 2001.

DANIELS, H.; ANGHILERI, J. Secondary mathematics and special educational needs. London: Cassell, 1995.

Educ. Soc., Campinas, vol. 27, n. 96 - Especial, p. 689-715, out. 2006 
Uma análise das condições para a implementação de políticas de educação...

DAVIE, R. Raising achievements of pupils with special educational needs. Support for Learning, London, v. 11, n. 2, p. 51-56, 1996.

DFEE. Excellence for all children: meeting special educational needs. London: HMSO, 1997.

DISABILITY RIGHTS COMISSION. Code of practice. London, 2001.

FERREIRA, M.C.C.; FERREIRA, J.R. Sobre inclusão, políticas públicas e práticas pedagógicas. In: Góes, M.C.R.; LaPLANE, A.L.F. Políticas e práticas de educação inclusiva. Campinas: Autores Associados, 2004.

FLORIAN, L. et al. What can national data sets tell us about inclusion and pupil achievement? British Journal of Special Education, London, v. 31, n. 3, p. 115-121, Sept. 2004.

GARNER, P. Exclusions: the challenge to schools. Support for Learning, London, v. 8, n. 3, p. 99-103, 1993.

GIDDENS, A. Modernity and self-identity. Cambridge: Polity, 1991.

HOBSBAWM, E. The age of extremes. London: Michael Joseph, 1994.

KASSAR, M.C.M. Matrículas de crianças com necessidades educacionais especiais: do que e de quem se fala. In: Góes, M.C.R.; LAPLANE, A.L.F. Políticas e práticas de educação inclusiva. Campinas: Autores Associados, 2004. p. 49-68.

LAPLANE, A.L.F. Interação e silêncio na sala de aula. Ijuí: Unijuí, 2000.

LAPLANE, A.L.F. Notas para uma análise dos discursos sobre inclusão escolar. In: Góes, M.C.R.; Laplane, A.L.F. Politicas e práticas de educação inclusiva. Campinas: Autores Associados, 2004a. p. 5-20.

LAPLANE, A.L.F. Contribuições para o debate sobre a política de inclusão. In: LODI, A.C. B.; HARRISON, K.M.P.; CAMPOS, S.R.L. Leitura e escrita no contexto da diversidade. Porto Alegre: Mediação, 2004b. p. 27-32.

OFFE, C. Contradictions of the Welfare State. London: Hutchinson, 1984.

OFSTED. Special educational needs and disability: towards inclusive schools. London: Crown, 2004. 
ORGANIZAÇÃO DAS NAÇÕES UNIDAS. Declaração Universal dos Direitos do Homem. New York: ONU, 1948.

ORGANIZAÇÃO DAS NAÇÕES UNIDAS. Declaração dos Direitos da Infância. New York: ONU, 1956.

PARSONS, C.; HOWLETT, K. Permanent exclusions from school: a case where society is failing its children. Support for Learning, London, v. 11, n. 3, p. 109-112, 1996.

ROUSE, M.; FLORIAN, L. Inclusive education in the marketplace. International Journal of Inclusive Education, London, v. 1, n. 4, p. 323-336, 1997.

SÃO PAULO. Conselho Estadual de Educação. Indicação 12/1999.

SÃO PAULO. Conselho Estadual de Educação. Deliberação 5/2000.

SÃO PAULO. Secretaria de Educação. Resolução 95, de 21/11/2000. Dispóe sobre o atendimento de alunos com necessidades educacionais especiais nas escolas da rede estadual de ensino e dá providências correlatas. Diário Oficial do Estado de São Paulo, São Paulo, 22 nov. 2000 .

SENNETT, R. The conscience of the eye. London: Faber \& Faber, 1991.

SPECIAL Educational Needs and Disability Act. London: The Stationery Office, 2001.

YOUNG, J. The exclusive society. London: Sage, 1999. 